\title{
A Case Study on Developing an EFFECTIVE INFORMATION BASED HEALTHCARE SERVICES - INDIA's SCENARIO
}

\author{
A. Pathanjali Sastri ${ }^{1}$, A. Sanatsujatha Misra ${ }^{2}$, G. Ramakoteswara Rao ${ }^{3}$, \\ B.D.C.N. Prasad ${ }^{4}$ \\ ${ }^{1}$ Department of Computer Application, V.R.Siddhartha Engineering College, \\ Kanuru, Vijayawada - 520 007, Andhra Pradesh, India. \\ akellapatanjali@yahoo.com \\ ${ }^{2}$ Assistant Consultant, TATA Consultancy Services, India. \\ sanatsujata@yahoo.com \\ ${ }^{3}$ Department of Information Technology, V.R.Siddhartha Engineering College, \\ Kanuru, Vijayawada - 520 007, Andhra Pradesh, India. \\ koti_g@yahoo.com \\ ${ }^{4}$ Department of Computer Application, Potluri V Prasad Siddhartha Institute of \\ Technology, Kanuru, Vijayawada - 520 007, Andhra Pradesh, India. \\ bdcnprasadegmail.com
}

\begin{abstract}
The real test of technological development is to ensure whether it reaches people and the most important task is to produce, manage and deliver relevant information systems appropriately within India. Therefore technology needs to be acquired and adapted for it to be appropriately developed. A country like India needs to adapt and develop information systems based on their own needs and structures, using their own methods and practices. When it comes to eGovernance projects, better cooperation is the need of the day both from public as well as private players [1]. The Indian government is taking greater cognizance of the benefits of technology and some e-Gov projects have already been initiated and deployed in few states of our country [1]. However, despite an improved Information Communication Technology (ICT) in our country thanks to the efforts of our government, there are still problems which continue to hamper the use of information and ICT in domain of healthcare in India [2]. This paper discusses the current levels of IT and quality in health care in our country and how Information Technology (IT) might be helpful in future.
\end{abstract}

\section{KEYWORDS}

Information Technology(IT), Information Communication Technology (ICT), Healthcare, Clinical Management Information Systems, Electronic Medical records, Telemedicine.

\section{INTRODUCTION}

The construction and evolution of large software systems, is of central importance in the applications of computer science. Health care organizations in our country currently invest less in IT compared with any other information-intensive industry such as banking and current systems are relatively primitive in few private super specialty hospitals. We could see an enterprise wide software solution in these hospitals cover functionalities like administration, clinical, support and back office. This paper reviews the process of some of the healthcare software deployed in few

Rupak Bhattacharyya et al. (Eds) : ACER 2013,

pp. 255-259, 2013. (C) CS \& IT-CSCP 2013

DOI : 10.5121/csit.2013.3223 
big hospitals (names not disclosed to maintain confidentiality), also draws from the experience (case studies), and highlights some lessons that may be useful for the development of Clinical Management Information Systems that will meet the operational, business and teaching/research needs of a hospital across India.

\section{Origin of the ReSEarch Problem}

Healthcare is a field of high developmental priority as the wealth of a nation depends on the health of its population. So in order to make the 'information society' have a real socio-economic impact in India, it must be applied in sectors like health care, Agriculture, education, etc. The changing scenario of the Indian healthcare industry has drastically changed the IT requirements of hospitals also. Indeed, between the health care that we now have, and the health care we could have, lies not just a gap, but a chasm [2]. There is a need for the Indian IT industry and healthcare organizations together make an important distinction by showing that the best strategy to develop ICT Enabled projects in the area of healthcare[3]. There are challenges within the current healthcare system that must be overcome [4].

The current challenges [5] are:

i) Low reach or inaccessibility or insufficiency of quality care to the most economically backward areas.

ii) Presence of specialist doctors is restricted to the metro and class-A cities.

iii) The risk of under-utilization of resources like beds, Doctors, Nurses etc.

iv) Isolated bits of patient and medical know-how across entities in the system.

v) Lack of a complete patient record.

vi) High cost and low productivity due to bottom-up re-creation of diagnosis or investigations for every instance.

vii) A majority of the hospitals in the country are still rooted in manual processes and unable to cope with the huge volume of data generated.

viii)In many of the hospitals they have either disparate systems running or some small systems developed in-house, which neither provide the desired results nor integrate with newer systems.

ix) In the bigger hospitals, patient records literally occupy lot of space and still remain difficult to access.

Given that, automation is the only solution that will liberate Indian hospitals from hassles like these and the system is expected to have extensive search and retrieval functions for patient cases which will be used in clinical research and also teaching.

The following key objectives are to be achieved by the fully automated system are:

a. For the administrative staff the system maintains and integrates information of hospital, hospital staff and patients.

b. Information systems (kiosks) should help in educating patients about the latest developments in medical science through the internet and also the facilities available in various hospitals and clinics across the country.

c. The medical researchers will have greater access to presenting problems, diagnosis, treatment and results.

d. The patients and doctors will receive a higher standard of information immediately on line.

e. The system allows the physician and medical students improve their efficiency by providing them with information that will help in research and analysis. 
f. Focus on not just "functionality", but "Functionality with a vision".

g. The long term goal is to build and maintain a patient database for analysis of data to facilitate decision making process.

Even though the first objective has been achieved to some extent in large private hospitals in metro cities [6] in our country, the use of information technology based medical services has fallen short of expectations of these Healthcare providers in the following aspects.

a. Planning and acquiring of resources, optimum resource utilizations and improved quality of services efficiently.

b. Assisting the Management to analyze the growth and profitability

c. Monitor return of investment on medical \& auxiliary facilities

d. Maintaining \& Monitoring the Quality of medical services

e. Managing the knowledge of each specific ailment

f. Accessing to patient related data and clinical images at the touch of a button to provide quality healthcare services [7] (ELECTRONIC MEDICAL RECORDS -EMR) and also facilitating real time Consultations through mobile unit at the door step of the Rural population[7] (TELEMEDICINE)

g. Utilizing Geographic Information Systems (GIS) in modelling disease risk and access to healthcare in developing countries in the light of public health, disease surveillance, and prevention efforts [8]

h. Bringing the professional closer to the necessary information and knowledge and at the same time channelling all gained experience towards a repository of this knowledge.

i. Cultivating professional relationships (IT \& Medical teams) and also understanding between groups of clinicians.

\section{HealthCARe From India’s Perspective - CuRrent Scenario}

An important and positive development has to take place in the Indian healthcare sector is the use of information technology for purposes such as computerization of medical records, networking of various departments in a hospital, providing of Tele-medicine services, Clinical Decision Support System[7]. A lot of innovation has to happen to provide primary remote consultations through mobile unit at the door step of the rural population and also underprivileged sections of the society. This will also help to take the expert opinion of specialists by means of video conference and also creating awareness among general population in rural area about various alarming diseases. This will result in having adequate information and knowledge available in an accessible manner at the right time and also in clinical decision-making in the shortest possible period of time, at the cheapest possible cost giving the best possible service to the patients. The following table shows how the benefits of an information technology based medical services providing integration between diagnoses, medical advice, prescription, medical education \& research and Pharmacy thus making the entire process of the healthcare services seamless and streamlined.

Table 1. benefits of an information technology based medical services

\begin{tabular}{|l|l|}
\hline $\begin{array}{c}\text { Automation Goals } \\
\text { And Operational } \\
\text { Priorities }\end{array}$ & \multicolumn{1}{c|}{ Explanation } \\
\hline $\begin{array}{l}\text { Excellence in } \\
\text { Education }\end{array}$ & $\begin{array}{l}\text { The Clinical Management Information System (CMIS) will provide } \\
\text { data storage and effective retrieval of case material allowing } \\
\text { medical students and researchers' easier access to case notes for } \\
\text { their projects and research. }\end{array}$ \\
\hline
\end{tabular}




\begin{tabular}{|l|l|}
\hline Excellence in Research & $\begin{array}{l}\text { CMIS will provide data storage and effective retrieval of case } \\
\text { material to allow the Doctors, Medicine's researchers' greater } \\
\text { access to presenting problems, diagnosis, treatment and results. }\end{array}$ \\
\hline Quality services & $\begin{array}{l}\text { Patients and referring consultants will receive a higher standard of } \\
\text { information as all case material, results, etc, will be available } \\
\text { immediately on line. }\end{array}$ \\
\hline $\begin{array}{l}\text { Quality knowledge } \\
\text { management }\end{array}$ & $\begin{array}{l}\text { Patients and referring consultants will receive a higher standard of } \\
\text { information as all case material, results, etc, will be available } \\
\text { immediately on line. }\end{array}$ \\
\hline $\begin{array}{l}\text { Building effective } \\
\text { partnerships and } \\
\text { collaborations }\end{array}$ & $\begin{array}{l}\text { The Researchers, Clinical community, Para-medical community, } \\
\text { and laboratory technicians have high collaborations in order to } \\
\text { bring out this system. }\end{array}$ \\
\hline
\end{tabular}

\section{SUMmary OF THE IMPROVEMENTS TO BE CONSIDERED IN IT BASED HEALTHCARE IN INDIA}

\subsection{Current Scenario of Indian Hospitals}

a. The scope of their usage is limited to administrative functions.

b. IT uptake is limited to custom developed software for areas like billing and patient scheduling.

c. Main benefits of computerisation enjoyed by the administrators and the management for MIS reports like the hospital occupancy, revenue generated by various departments etc.

d. The doctors very rarely use computers to see their patients condition/progress online

\subsection{Improvements Required}

a. Bridge the gap by building software required to manage the huge amount of patient related data in a cost and time effective manner on the existing infrastructure.

b. Assist Management and Physicians/Consultants in decision making

c. Computerisation should help in education and research.

d. Meet the requirements of the managers and the clinicians by providing them with information that will help in research and analysis.

\section{Conclusions}

The primary objective of this study is to create an empirical research-based view of the impact of computerization in Indian healthcare industry and to develop appropriate systems in India taking into account the socio-economic impact, and to encourage IT and healthcare community participation to strengthen the Health Informatics Research in India. The e-governance projects should also focus on the development of useful products, both clinical use and health management in addition to other projects taken.

\section{REFERENCES}

[1] http://egovindia.wordpress.com/category/egovernance-projects-around-country/

[2] Institute of Medicine: Crossing the Quality Chasm: A New Health System for the 21st Century: Washington, DC, National Academy Press 2001

[3] Pushwaz Virk, Sharib Khan, Vikram Kumar, "India HIT Case Study", The Healthcare Sector Report. 2006 
[4] http://www.iimahd.ernet.in/egov/documents/impact-assessment-study-dit.pdf

[5] http://www.asianhhm.com/information_technology/healthcareit_india.htm

[6] Mohanty Rajesh, Rana Sarosh D, Kolay Saroj K, "HOSPITAL INFORMATION SYSTEM IN MEDICARE AN EXPERIENCE AT TATA MAIN HOSPITAL, JAMSHEDPUR"

[7] Information technology and health care in Canada: 2007 Status report

[8] Imelda Moise, Ezekiel Kalipeni, Jayati Ghosh, "A Third World Perspective on GIS Applications in Health: The Case of Zambia's HIV/AIDS Surveillance Data"

\section{AUTHORS}

Mr. A.Pathanjali Sastri is currently pursuing Ph.D Computer Science from Raylaseema University, Kurnool. He is woking as an Assistant Professor in Velagapudi Siddhartha Engineering College since 2008 and has 10+ years of Industrial experience prior to this. He has published papers in reputed international journals and conferences. His area of interest includes Software Engineering, Project Management, Quality Assurance and Control, Artificial Intelligence and RDBMS.

Mr. A. Sanat Sujata Misra is currently working as an Assistant Consultant in TATA Consultancy Services, Chennai since 2003 and has 15+ years of Industrial experience and held various positions. His area of interest includes Software Engineering, Quality Assurance and Control, Project Management, and RDBMS.

Dr. G. Ramakoteswara Rao is having 17+ years of experience as a faculty member in Department of Computer Science. He worked as a Professor and Head in Department of Computer Science, P.B.Siddhartha College, Vijayawada and currently is working as as a Professor in Department of Information Technology at V.R.Siddhartha Engineering College. He is having publications in various national and international journals / conferences. He is an active researcher in area of network security and his areas of interest include operating systems and network security.

Dr. B.D.C.N.Prasad, currently is a Professor \& Head, Department of Computer Applications at Prasad V. Potluri Siddhartha Institute of Technology, Vijayawada, Andhra Pradesh, India. He received Ph.D in Applied Mechanic from Andhra University, Visakhapatnam, A.P, India in 1984. His research interest includes Data Mining, Rough Sets in Computer Science and Boundary Value Problems and Fluid Dynamics in Mathemtics. He has several publications in Mathematics and Computer Science in reputed national and International journals. He is a member of ISTAM and ISTE. He is a
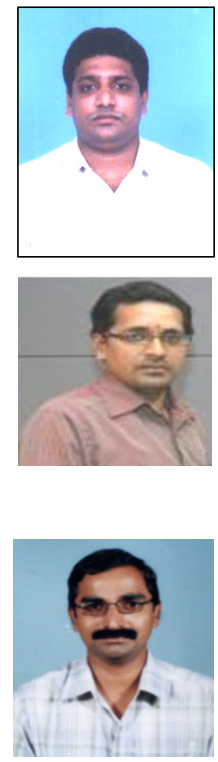
national executive member of Indian Society for Rough Sets.

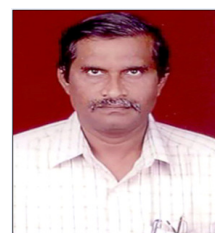

